\title{
Adhesion and proliferation of human dental pulp stem cells on a laser microtextured implant surface: An in vitro study
}

\author{
Enrico Conserva*, Ugo Consolo and Pierantonio Bellini \\ Department of Surgery, Medicine, Dentistry and Morphological Sciences with interest in Transplant, Oncology and Regenerative Medicine, University of Modena \\ and Reggio Emilia, Modena, Italy
}

\begin{abstract}
The roughness of the implant surface and its chemistry and topography were demonstrated to impact cells biological properties. A moderate roughness seems to allow better and faster adhesion and proliferation and to accelerate the biological processes. The different physical and chemical procedures used to obtain a certain microtopography modify the surface chemical composition and, in consequence of it, can affect the biological cell behavior. The ideal surface should be obtained through processes that do not modify the chemical composition maintaining a right roughness and microtopography. The aim of this investigation was to study the morphology, proliferation and pattern of distribution of human Dental Pulp Stem Cells (hDPSCs) after 5 days of growth on a laser micro-grooved implant surface (Laser-Lock, Bio Horizons IPH, Inc. Birmingham, AL 35244, USA) characterized by a micro geometric design obtained by computer-aided laser ablation without any chemical treatment. Data from SEM surface observation and XPS chemical analysis have highlighted the absence of contaminating chemical elements. The results from cell cultures indicated that the hDPSCs maintained a good morphology and well proliferated following the microgrooves direction.
\end{abstract}

\section{Introduction}

The interaction between cells and implant surfaces plays an essential role in the field of dental surgery. Osseointegration process consists in the ability of bone marrow mesenchymal stem cells to adhere to the implant and becoming mature osteoblasts [1]. It is well known that this process is influenced by different events, such as the microtopography and the chemical composition of implants surfaces [2-4]. As a matter of fact, the roughness of the implant surface and its chemistry and topography were demonstrated to impact cells biological properties [5]. A moderate roughness seems to allow better and faster adhesion and proliferation, but the different physical and chemical procedures used to obtain a certain microtopography (such as sandblasting, acid etching, oxidizing, machining, Nano incorporation) leave contaminants that modify the surface chemical composition and, in consequence of it, can influence the biological cell behavior [3,69]. The ideal surface should be obtained through processes that do not modify its chemical composition maintaining the right degree of roughness and a cell-attractive microtopography.

Different cell sources have been studied in vitro to evaluate how surface properties might affect osseointegration [10]. In recent years, interest has grown significantly in stem cell research due to stem cells ability to regenerate lost and injured tissue, especially in the craniofacial field, where the rehabilitation of this complex anatomical district represents a challenging situation for surgeons and dentists $[11,12]$. Human Dental Pulp Stem cells (hDPSCs) are commonly identified by a distinct surface phenotype as well as by their potential to differentiate into specific lineages in vitro. Human dental pulp, a soft connective tissue contained within the pulp chamber of the tooth, is considered an interesting source of adult stem cells, due to the low-invasive procedures required for cell isolation, high content of stem cells and its peculiar embryological origin from neural crest [13-15]. Particularly, neural crest cells originate during the formation of neural tube, at the 3rd week of embryo development, then undergo an epithelial mesenchymal transition (EMT) and migrate to different body compartments under the control of several positive and negative regulatory factors [16]. Following migration, neural crest cells generate the majority of craniofacial tissues, including tooth, fat, muscle, bone and cartilage tissues, as well as cranial peripheral ganglia and nerves, among other cell types, such as melanocytes. The differentiation potential of neural crest cells toward several lineages allows to consider the neural crest as the fourth germ layer. Based on their location within dental pulp, they can be easily isolated and might therefore be applied to cell therapy approaches for the regeneration of craniofacial injuries [17]. As well documented in literature, due to the heterogeneous nature of human dental pulp stem cells, distinct markers were used to select different subsets of stem cells, with different related behaviors, therefore it would be desirable, for regenerative medicine purposes, to obtain immunophenotypically pure stem cell populations. It has been widely demonstrated that, under appropriate stimuli, hDPSCs are able to differentiate toward osteogenic, myogenic and adipogenic lineages, islet like insulin producing b-cells, melanocytes, Schwann cells and

${ }^{\star}$ Correspondence to: Enrico Conserva, Assistant Professor, Department of Surgery, Medicine, Dentistry and Morphological Sciences with interest in Transplant, Oncology and Regenerative Medicine, University of Modena and Reggio Emilia, Modena, Italy, E-mail: studioconserva@libero.it

Key words: dental pulp stem cells, implant surface, laserized surface, microgrooves, microchannels

Received: December 21, 2018; Accepted: December 28, 2018; Published: December 31, 2018 
neuronal lineage [18-24]. The aim of this investigation is to study the morphology, proliferation and pattern of distribution of hDPSCs after 5 days of growth on titanium disks treated by Laser-Lock surface, (Bio Horizons IPH, Inc. Birmingham, AL 35244 USA) a unique well-defined micro-grooved implant surface produced by using computer-aided laser ablation technique. The surface-controlled microgeometries, in specific size ranging between $2 \mu \mathrm{m}$ and $12 \mu \mathrm{m}$, seem to enhance bone integration and control the local microstructural geometry of attached bone $[25,26]$.

\section{Materials and methods}

This study was carried out in accordance with the recommendations of the Ethic Committee, University of Modena (Modena, Italy), which provided the approval of the protocol (ref. number 3299/CE). Human DPSCs were isolated from third molars of adult subjects $(n=3 ; 19-28$ years). All subjects gave written informed consent in accordance with the Declaration of Helsinki. Cells were isolated from dental pulp as described by Pisciotta, et al. [20] (Figure 1). Briefly, dental pulp was harvested from the teeth and underwent enzymatic digestion by using a digestive solution, consisting in $3 \mathrm{mg} / \mathrm{mL}$ type I collagenase plus $4 \mathrm{mg} /$ $\mathrm{mL}$ dispase in a-MEM. Pulp was then filtered onto $100 \mu \mathrm{m}$ Falcon Cell Strainers, in order to obtain a cell suspension. Cell suspension was then plated in $25 \mathrm{~cm} 2$ culture flasks and expanded in culture medium [ $\alpha$-MEM supplemented with $10 \%$ heat inactivated fetal bovine serum (FBS), 2 $\mathrm{mM}$ L-glutamine, $100 \mathrm{U} / \mathrm{mL}$ penicillin, $100 \mu \mathrm{g} / \mathrm{mL}$ streptomycin] at $37 \bigotimes \mathrm{C}$ and $5 \% \mathrm{CO}_{2}$. Following cell expansion, human DPSCs underwent magnetic cell sorting through MACS R separation kit. Two subsequent immune-selections were performed by using primary antibodies: mouse IgM anti-STRO-1 and rabbit IgG anti-c-Kit (Santa Cruz). The following magnetically labelled secondary antibodies were used: antimouse IgM, anti-rabbit IgG and anti-mouse IgG (Miltenyi Biotec).
Firstly, cell suspension was selected by using antiSTRO-1 antibody. STRO-1+ hDPSCs were expanded and then selected by using anti-cKit antibody to obtain a STRO1+/cKit+ population. Before starting to seed the cells over the laserized disks, the surface was characterized by SEM at 800x and 2000x of magnification and the chemical composition was analyzed by EDX (Energy Dispersive X-ray Analysis). Moreover, we used the XPS technology (X-ray Photoelectron Spectroscopy) that allows to obtain a qualitative and quantitative composition (atomic \%) of the outer material layers (in case of metals, the depth analyzed is about 5 nanometers) that actually come in contact with the bone tissue. The XPS analysis was performed with a Perkin Elmer PHI 5400 ESCA System. It is equipped with an $\mathrm{X}$-ray source ( $\mathrm{Mg}$ anode), maintained at $10 \mathrm{kV}$ with a power of $200 \mathrm{~W}$. The pressure inside the analysis chamber was maintained at about $10^{-8} \mathrm{~Pa}$.

Three disks were used for this purpose. Undifferentiated hDPSCs were seeded at a density of $2.5 \times 10^{3} \mathrm{cells} / \mathrm{cm}^{2}$ on titanium laser microgrooved disks in a 12-multiwell unit. For the 5 days experimental time six disks were used. Cells were cultured in standard conditions and maintained in expansion medium (a-MEM, 20\% FBS, 1\% L-glutamine, $1 \%$ penicillin and streptomycin - all from Sigma Aldrich, Saint Louis, MO, USA). At the end of experimental time, the cells were fixed in ice-cold paraformaldehyde $4 \%$ for 15 minutes without dissociating them from the titanium disks. The cells were subsequently permeabilized with $0.1 \%$ Triton X-100 in PBS for 5 minutes, stained with TRITC-conjugated anti-phalloidin antibody (Life Technologies, Carlsbad, USA) and rinsed with PBS. Nuclei were stained with $1 \mu \mathrm{g} /$ $\mathrm{mL}$ 4',6-diamidino-2-phenylindole (DAPI) in PBS. DABCO was used as anti-fading mounting medium. Cell morphology, proliferation and pattern of distribution were assessed through a Nikon A1 confocal laser scanning microscope.

\title{
Human Dental Pulp Stem Cells (hDPSCs)
}

\author{
1. Derived from ectomesenchyme \\ 2. Isolation procedures easy \\ 3. Immunomodulation \\ 4. Cells Multipotent
}
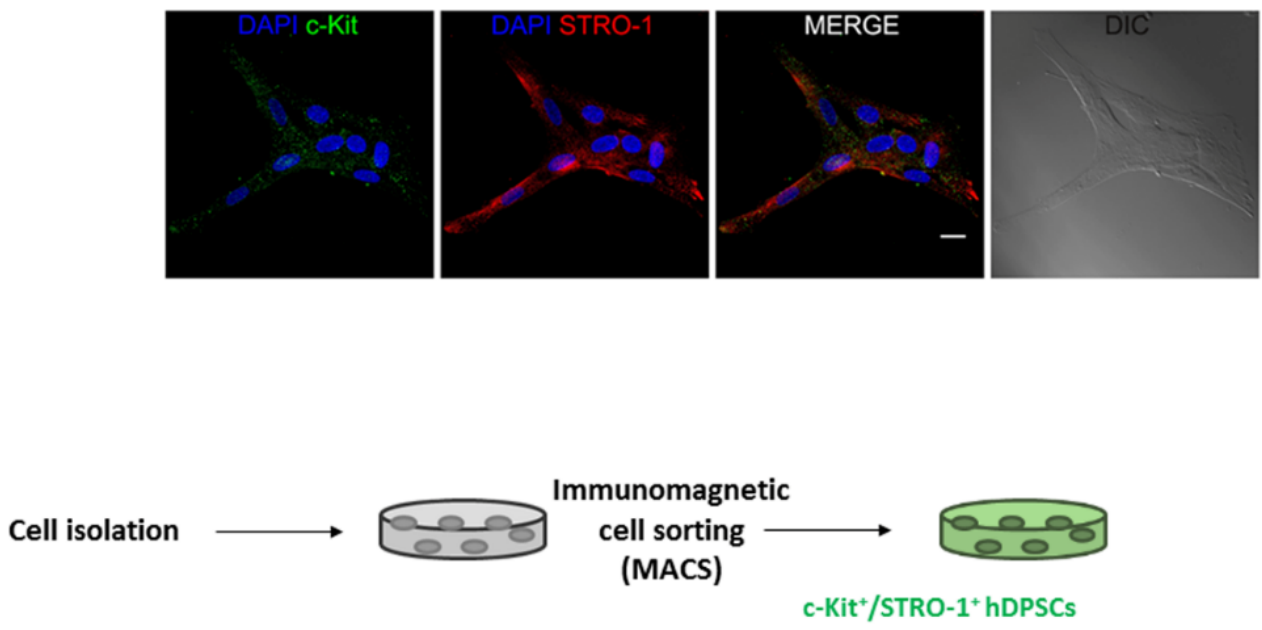

Figure 1. Isolation of hDPSCs: working flow 


\section{Results}

The SEM observation showed that the computer-aided laser ablation process creates a typical surface design with microgrooves of $8 \mu \mathrm{m}$ with a repeat spacing, or pitch, of $16 \mu \mathrm{m}$ (Figures 2 and 3). The "repeat spacing" is the distance comprising one groove and one ridge between the grooves [27]. These microgrooves give the surface a characteristic three-dimensional scaffold shape, with square wave profiles, that exert a strong cellular contact guidance effect [25]. This microgeometry results to be very different from the micro-nano topographies obtained through physical-chemical procedures and the surface appeared very clean without any residue from the laser ablation process.

The EDX (Figure 4) and XPS (Figure 5 and Table 1) analyses, in fact, revealed the only presence of Oxygen, Titanium and Carbon (always under 40\%). The Carbon derives from the presence of $\mathrm{CO}_{2}$ molecules that are inevitably present in the earth's atmosphere. The surface of the metals combines itself with these molecules (the technical term is "adsorption") that can be detected only by a specific surface analysis like the XPS, while they are "invisible" using the more traditional methods of analysis. Carbon can also derive from an "heavy" contamination, such as contact with oils or other lubricating fluids during processing. To discern between C "natural" and C "from contamination" it is necessary to take into consideration the quantitative aspect. Percentages of $30-40 \%$ are physiological and can be considered normal. Higher percentages indicate the presence of a Carbon contamination leading to an increase in surface tension $(Y)$ and consequently to a decrease in surface wettability $(\theta)$ [28]. hDPSCs morphology, proliferation and orientation was assessed by confocal microscopy. After 5 days of culture on Laser-Lok surfaces, hDPSCs did

Table 1. Surface composition (atomic\%) obtained by XPS analysis and the Carbon/ Titanium ratio

\begin{tabular}{|c|c|c|c|c|c|c|c|c|c|c|c|}
\hline Specimen & $\mathbf{C}$ & $\mathbf{O}$ & $\mathbf{T i}$ & $\mathbf{N}$ & $\mathbf{S}$ & $\mathbf{S i}$ & $\mathbf{P}$ & $\mathbf{C a}$ & $\mathbf{A l}$ & $\mathbf{C l}$ & $\mathbf{C} / \mathbf{T i}$ \\
\hline \# 1 & 38.2 & 40.7 & 19.8 & - & - & - & - & - & - & - & 1.93 \\
\hline \# 2 & 38.4 & 41.5 & 19.5 & - & - & - & - & - & - & - & 1.97 \\
\hline \# 3 & 39.1 & 39.3 & 19.6 & - & - & - & - & - & - & - & 1.99 \\
\hline
\end{tabular}

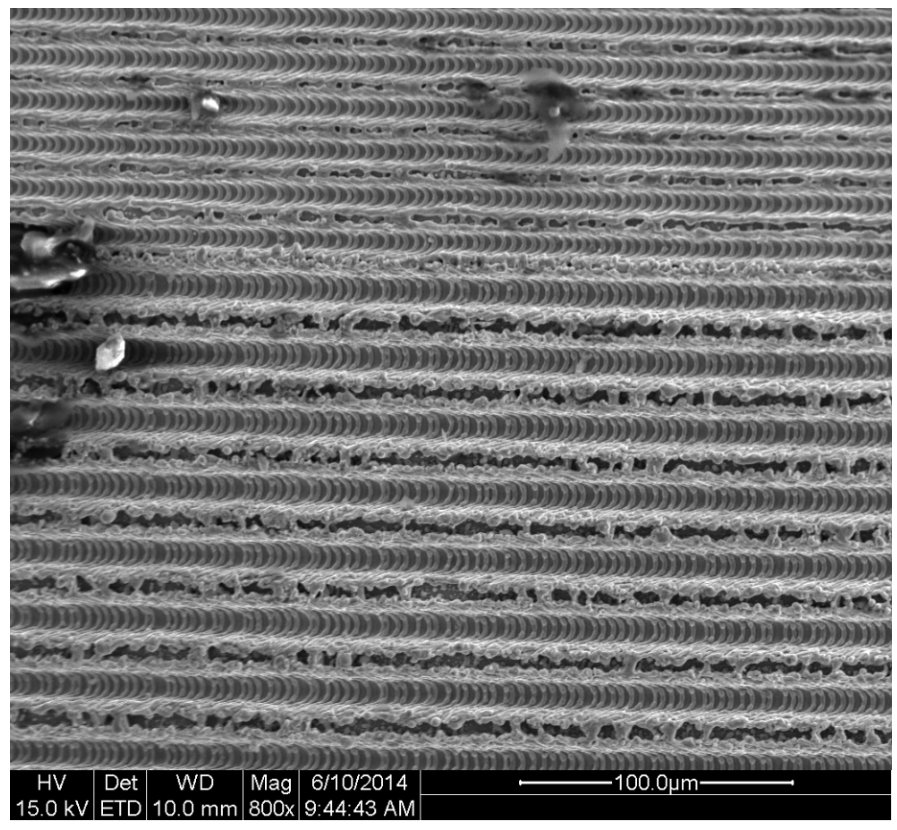

Figure 2. SEM image of the laserized surface at $800 \mathrm{x}$ magnification

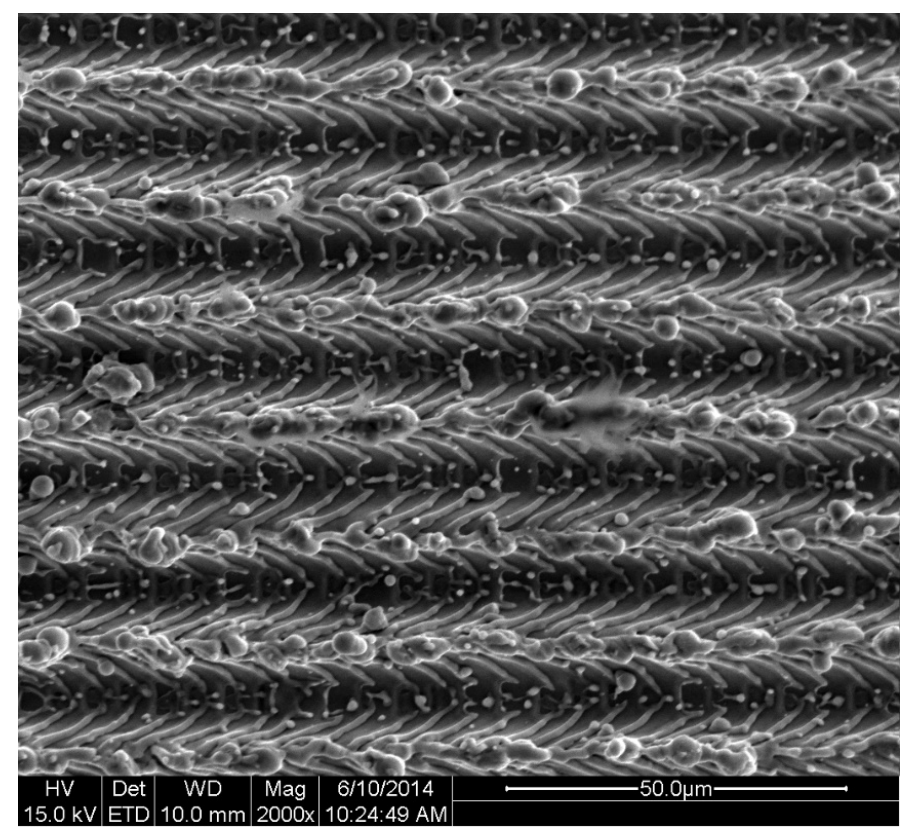

Figure 3. SEM image of the laserized surface at 2000x magnification

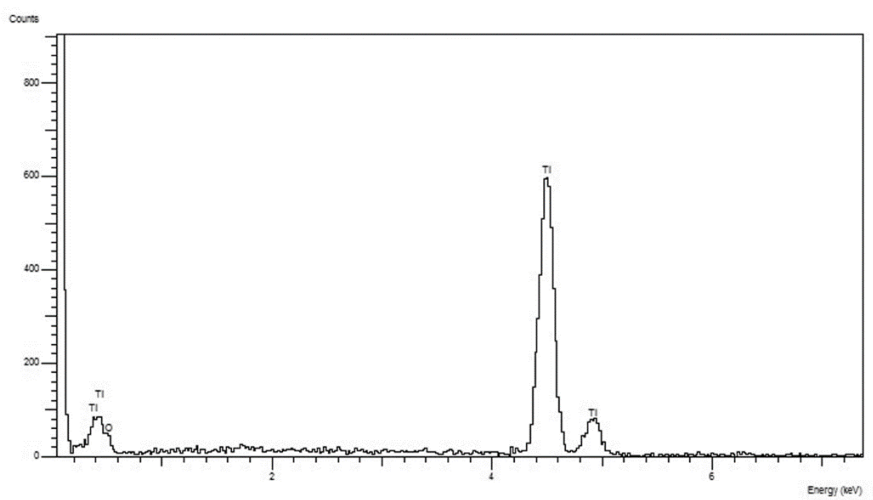

Figure 4. EDX analysis that showed the only presence of Titanium and Oxygen

not show any signs of suffering. Particularly nuclei appear euchromatic and the cells are well proliferated and aligned with the grooves obtained by the laser (Figure 6). After 5 days the hDPSCs covered all the disk surface and this indicates that cells are well stimulated by this special laserized micro design (Figure 7).

\section{Discussion}

Cellular adhesion, proliferation and differentiation is influenced by the properties of titanium implants, including their surface microtopography and their surface chemistry or surface energy/ wettability [4]. Esposito, et al. [29] reported that implants with various degrees of surface roughness may not behave in the same way but some of these provide better results than others. Further studies supported this statement and concluded that moderately rough surfaces give rise to faster osseointegration than turned implant surfaces $[3,30]$. In other studies, all the rough surfaces investigated showed quick cell adhesion and proliferation and induced an early level of osteoblast differentiation. The machined surfaces were competitive but showed a slowdown of all the biological processes [8,9]. For these reasons implants with moderately rough surfaces are today widely used, but the processes to obtain the surface microtopography modify not only the 


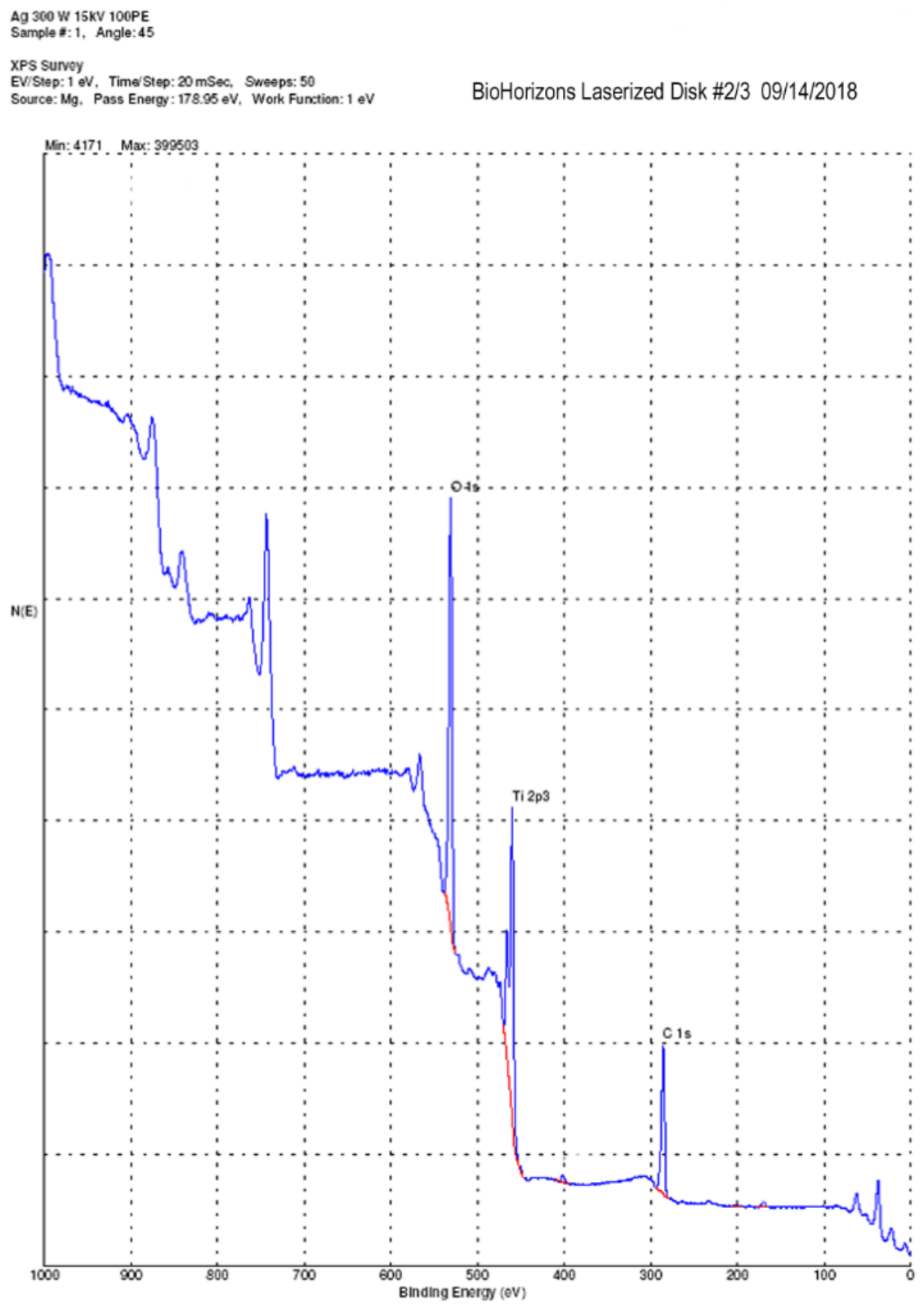

Figure 5. XPS surface analysis: only $\mathrm{Ti}, \mathrm{O}$ and $\mathrm{C}$ are detectable
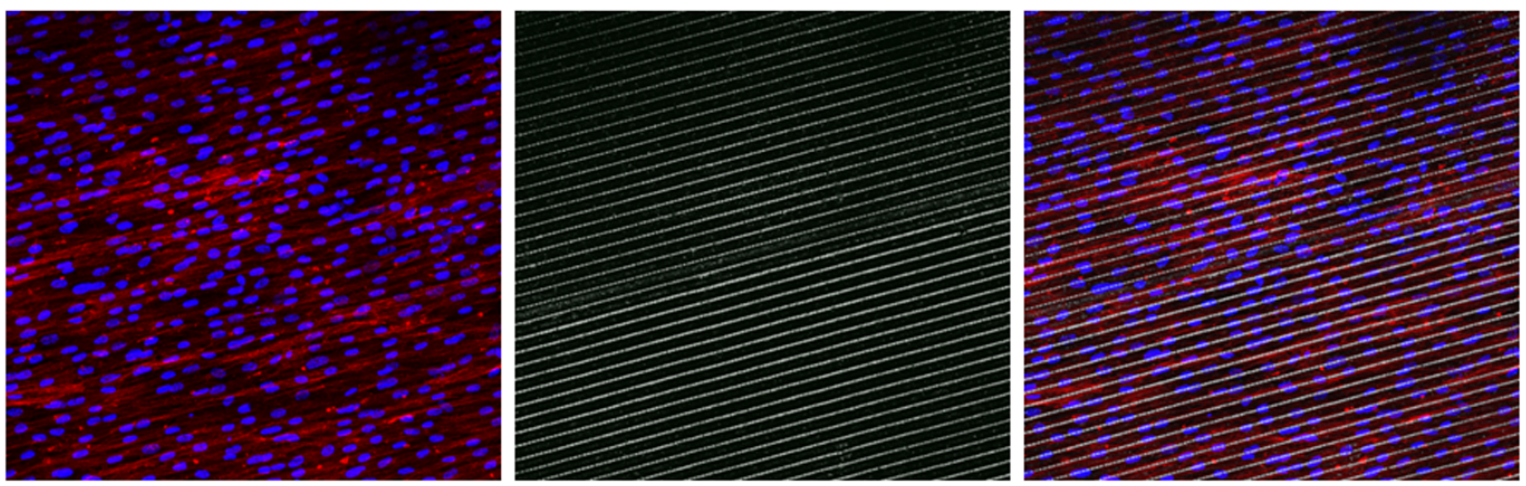

Figure 6. Confocal microscopy image of DPSCs grown on two Laser-Lock disks 


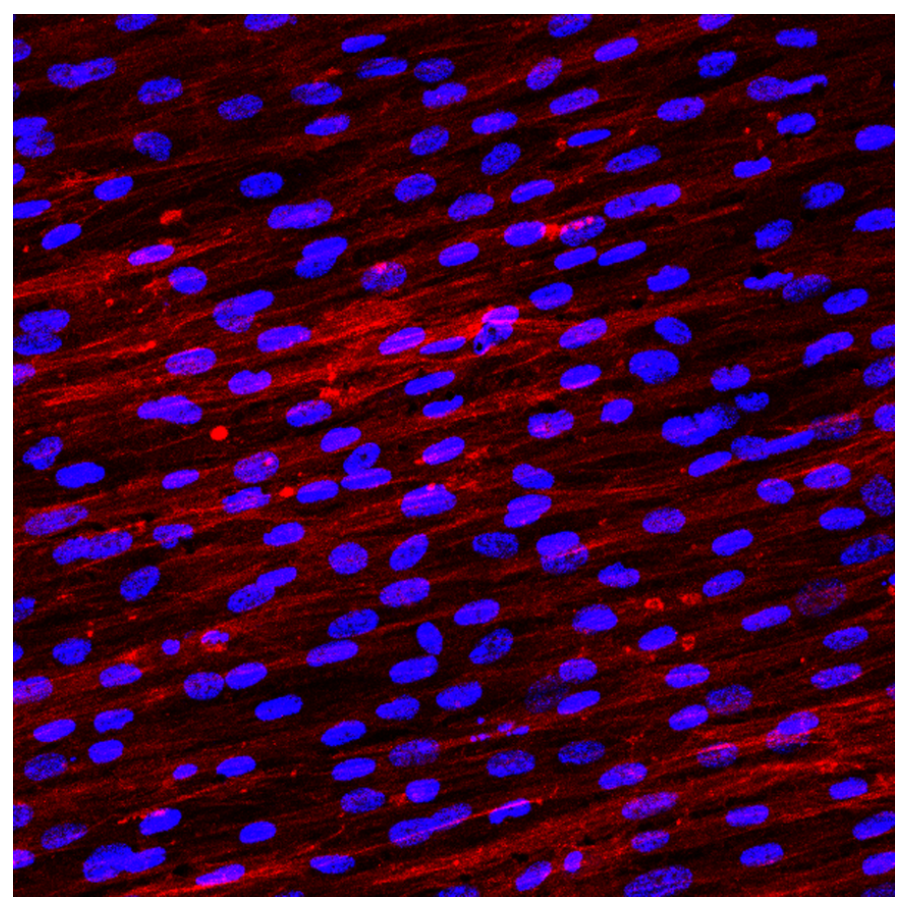

Figure 7. Confocal microscopy image of DPSCs grown on a Laser-Lock disk (digital magnification)

surface roughness but also its chemical composition and influence the expression of several genes involved into osteogenetic processes [31].

Morra and Casinelli [6,7] investigated 34 different commercially available titanium dental implants analyzing their surface characteristics and especially the chemical compositions by XPS analysis. They found a lot of elements, other than $\mathrm{Ti}, \mathrm{O}$ and $\mathrm{C}$, back to cleaning and washing procedures (magnesium, sodium, chlorine, phosphorus, calcium), contact with tools (zinc), acid etching (nitrogen, fluorine) and sandblasting (aluminum, calcium). The percentage of $\mathrm{Ti}$ was ranging between $1.4 \%$ and $18.3 \%$. In this study we found a percentage of $\mathrm{Ti}$ always above $19 \%$. It was suggested that about $18 \%$ surface concentration of $\mathrm{Ti}$ is a reasonable value for clean titanium surfaces in the normal environment [32]. Another important parameter to be considered is the carbon/titanium ratio that should be as low as possible (ideal value $\sim 1$ ) For example in case of a machined surface with an atomic percentage of $66.5 \%$ of $\mathrm{C}$ and $4.7 \%$ of $\mathrm{Ti}$, the $\mathrm{C} / \mathrm{Ti}$ ratio is 14.15.[6] The Laser-Lock surfaces analyzed in this study showed a $\mathrm{C} / \mathrm{Ti}$ ratio of 1.9 , an high percentage of $\mathrm{Ti}$ and no other contaminants normally left by cleaning, washing, etching, machining, sandblasting processes.

Laser-Lock surface appeared during SEM observation such as a geometrically organized implant surface. Its typical design pattern is produced by pulsed, computer-controlled, EXCIMER laser ablation, using a large-area masking technique. Laser-Lok showed a series of uniform precision-engineered cell-sized channels laser machined. This design allows to establish a true physical connective and bone tissue attachment preserving the coronal level of the bone [26]. Compared to microthreads, that are clearly visible at $30 \mathrm{x}$ magnification, microchannels are detectable only at higher magnifications. Ricci, et al. [26] found that a laserized surface exhibited more extensive bone ingrowth and osteoblast attachment than roughly surfaces and a directional control of bone attachment. The controlled microgeometries obtained by laser ablation ( $8 \mu \mathrm{m}$ sized microgrooves or microchannels) could enhance bone integration and control the local microstructural geometry of attached bone. After 5 days in contact with the laserized surface hDPSCs used in this study have grown without particular morphological changes and showed no signs of suffering. The cells showed the same pattern of growth previously described confirming that the surface microgrooves can determine the cell direction during proliferation. This could mean that we could be able to guide the direction of the proliferation of the bone cells during the osteogenic processes. Further studies will be needed to better understand the biological mechanisms underlying the behavior of hDPSCs in contact with the laser microtextured surface and, above all, to identify the genes involved in the regulation of these mechanisms.

\section{Aknowledgements}

Immunofluorescence analisys was supported by Dr. Gianluca Carnevale, Dr. Laura Bertoni and Dr. Alessandra Pisciotta, Department of Surgery, Medicine, Dentistry and Morphological Sciences: Center for Histology, University of Modena and Reggio Emilia.

\section{Reference}

1. Terheyden H, Lang NP, Bierbaum S, Stadlinger B (2012) Osseointegration-communication of cells. Clin Oral Implants Res 23: 1127-1135. [Crossref]

2. Mavrogenis AF, Dimitriou R, Parvizi J, Babis GC (2009) Biology of implant osseointegration. J Musculoskelet Neuronal Interact 9: 61-71. [Crossref]

3. Wennerberg A, Albrektsson T (2009) Effects of titanium surface topography on bone integration: a systematic review. Clin Oral Implants Res 20 Suppl 4: 172-184. [Crossref]

4. Feller L, Jadwat Y, Khammissa RAG, Meyerov R, Schechter I, et al. (2015) Cellular Responses Evoked by Different Surface Characteristics of Intraosseous Titanium Implants. BioMed Res Int.

5. Jemat A, Ghazali MJ, Razali M, Otsuka Y (2015) Surface Modifications and Their Effects on Titanium Dental Implants. BioMed Res Int.

6. Morra M, Cassinelli C, Bruzzone G, Carpi A, Di Santi G, et al. (2003) Surface chemistry effects of topographic modification of titanium dental implant surfaces: 1 . Surface analysis. Int J Oral Maxillofac Implants 18: 40-45. [Crossref]

7. Cassinelli C, Morra M, Bruzzone G, Carpi A, Di Santi G, et al. (2003) Surface chemistry effects of topographic modification of titanium dental implant surfaces: 2 . In vitro experiments. Int J Oral Maxillofac Implants 18: 46-52. [Crossref]

8. Conserva E, Lanuti A, Menini M (2010) Cell behaviour related to implant surfaces with different microstructure and chemical composition: an in vitro analysis. Int J Oral Maxillofac Implants 25: 1099-1107. [Crossref]

9. Conserva E, Menini M, Ravera G, Pera P (2013) The role of surface implant treatments on the biological behavior of SaOS-2 osteoblast-like cells. An in vitro comparative study. Clin Oral Implants Res 24: 880-889. [Crossref]

10. Hempel U, Hefti T, Dieter P, Schlottig F (2013) Response of human bone marrow stromal cells, MG-63, and SaOS-2 to titanium-based dental implant surfaces with different topography and surface energy. Clin Oral Implants Res. 24: 174-182. [Crossref]

11. Mao JJ, Prockop DJ (2012) Stem cells in the face: tooth regeneration and beyond. Cell Stem Cell 11: 291-301. [Crossref]

12. Foschi F, Conserva E, Pera P, Canciani B, Cancedda R, et al. (2012) Graft materials and bone marrow stromal cells in bone tissue engineering. J Biomater Appl 26: 10351049. [Crossref]

13. Goldberg M, Smith AJ (2004) Cell and extracellular matrices of dentin and pulp: biological basis for repair and tissue engineering. Crit Rev Oral Biol Med 15: 13-27.

14. d'Aquino R, De Rosa A, Laino G, Caruso F, Guida L, et al. (2009) Human dental pulp stem cells: from biology to clinical applications. J Exp Zool B Mol Dev Evol 312B 408-415. [Crossref]

15. Tirino V, Paino F, De Rosa A, Papaccio G (2012) Identification, isolation, characterization, and banking of human dental pulp stem cells. Methods Mol Biol 879: 443-463. [Crossref]

16. Shyamala K, Yanduri S, Girish HC, Murgod S (2015) Neural crest: The fourth germ layer. J Oral Maxillofac Pathol 19: 221-229. [Crossref] 
17. Trainor PA (2010) Craniofacial birth defects: the role of neural crest cells in the etiology and pathogenesis of Treacher Collins syndrome and the potential for prevention. Am J Med Genet A 152A: 2984-2994. [Crossref]

18. Paino F, La Noce M, Giuliani A, De Rosa A, Mazzoni S, et al. (2017) Human DPSCs fabricate vascularized woven bone tissue: a new tool in bone tissue engineering. Clin Sci 131: 699-713. [Crossref]

19. Paino F, Ricci G, De Rosa A, D’Aquino R, Laino L, et al. (2010) Ecto-mesenchymal stem cells from dental pulp are committed to differentiate into active melanocytes. Eur Cell Mater 20: 295-305. [Crossref]

20. Pisciotta A, Riccio M, Carnevale G, Beretti F, Gibellini L, et al. (2012) Human serum promotes osteogenic differentiation of human dental pulp stem cells in vitro and in vivo. PLoS One 7: e50542. [Crossref]

21. Pisciotta A, Carnevale G, Meloni S, Riccio M, De Biasi S, et al. (2015) Human dental pulp stem cells (hDPSCs): isolation, enrichment and comparative differentiation of two sub-populations. BMC Dev Biol 14:15. [Crossref]

22. Carnevale G, Riccio M, Pisciotta A, Beretti F, Maraldi T, et al. (2013) In vitro differentiation into insulin-producing b-cells of stem cells isolated from human amniotic fluid and dental pulp. Dig Liver Dis 45: 669-676. [Crossref]

23. Carnevale G, Pisciotta A, Riccio M, Bertoni L, De Biasi S, et al. (2016) Human dental pulp stem cells expressing STRO-1, c-kit and CD34 markers in peripheral nerve regeneration. J Tissue Eng Regen Med 12: e774-e785. [Crossref]
24. Aurrekoetxea M, Garcia-Gallastegui P, Irastorza I, Luzuriaga J, Uribe-Etxebarria V (2015) Dental pulp stem cells as a multifaceted tool forbioengineering and the regeneration of craniomaxillofacial tissues. Front Physiol 6: 289. [Crossref]

25. Clark P, Connolly P, Curtis AS, Dow JA, Wilkinson CD (1990) Topographical contro of cell behaviour II: multiple grooved substrata. Development 108: 635-644. [Crossref]

26. Ricci JL, Charvet J, Frenkel SR, Change R, Nadkarni P, et al. (2000) Bone response to laser microtextured surfaces In Bone Engineering, Chapt. 25; 282-292 em squared inc. Toronto, Canada.

27. Chehroudi B, Gould TRL, Brunette DM (1989) Effects of a grooved titanium-coated implant surface on epithelial cell behaviour in vitro and in vivo. J Biomed Mater Res 23: 1067-1085. [Crossref]

28. Kasemo B, Lausmaa J (1986) Surface science aspects of inorganic biomaterials. CRC Crit. Rev. Biocomp. 2; 335-380.

29. Esposito M, Coulthard $P$, Thomsen $P$, Worthington $H$ (2005) Interventions for replacing missing teeth: different types of dental implants. In: The Cochrane Collaboration, editor. Cochrane Database of Systematic Reviews, Chichester, UK.

30. Botticelli D, Lang NP (2017) Dynamics of osseointegration in various human and animal models - a comparative analysis. Clin Oral Implants Res 28: 742-748. [Crossref]

31. Conserva E, Borghi F, Consolo U (2017) Genetic Expression of SaOS2 cells grown on two different Implant Surfaces: An in vitro study. J Dent Oro Surg 2: 127.

32. Morra M, Cassinelli C (1997) Evaluation of surface contamination of titanium denta implants by LV-SEM: comparison with XPS measurements. Surf Interf Anal 25: 983-988.

Copyright: $\odot 2018$ Conserva E. This is an open-access article distributed under the terms of the Creative Commons Attribution License, which permits unrestricted use, distribution, and reproduction in any medium, provided the original author and source are credited. 